\title{
Severe inflammatory ileitis resulting in ileal perforation in association with combination immune checkpoint blockade for metastatic malignant melanoma
}

\author{
Ali Abdulnabi Mohamed, ${ }^{1,2}$ Cathy J Richards, ${ }^{3}$ Kirsten Boyle, $^{4}$ Guy Faust $^{5}$
}

\begin{abstract}
${ }^{1}$ Department of Oncology, University Hospitals of Leicester NHS Trust, Leicester, UK ${ }^{2}$ Leicester Cancer Research Centre, University of Leicester, Leicester, UK

${ }^{3}$ Department of Pathology, University Hospitals of Leicester NHS Trust, Leicester, UK ${ }^{4}$ Department of Surgery, University Hospitals of Leicester NHS Trust, Leicester, UK ${ }^{5}$ Department of Oncology, University Hospitals of Leicester, Leicester, UK
\end{abstract}

\section{Correspondence to} Dr Ali Abdulnabi Mohamed, ali-abdulnabi.mohamed@nhs. net

Accepted 21 March 2018

\section{Check for updates}

To cite: Mohamed AA, Richards CJ, Boyle K, et al. BMJ Case Rep Published Online First: [please include Day Month Year] doi:10.1136/bcr-2018224913

\section{SUMMARY}

Immune checkpoint inhibitors have become standard of care in metastatic malignant melanoma management. Despite superior effectiveness to chemotherapy, significant immune-related adverse events (irAE) may occur, particularly if used in combination. Gastrointestinal irAEs were reported with different patterns of involvement. Here, we report the case of a patient who had ileal perforation as a complication of terminal ileitis, without colitis, induced by combination immune checkpoint blockade.

\section{DESCRIPTION}

Immune checkpoint inhibitors have become standard of care in metastatic malignant melanoma management. Despite superior effectiveness to chemotherapy, significant immune-related adverse events (irAE) may occur, particularly if used in combination. $^{1}$ Gastrointestinal irAEs induced by anti-CTLA-4 and anti-PD-1 agents and their patterns were reported by Marthey et $\mathrm{al}$ and Collins et al, respectively. ${ }^{2}$ Although a few patients had evidence of ileitis, none of these cases reported resulted in ileal perforation. There were five cases

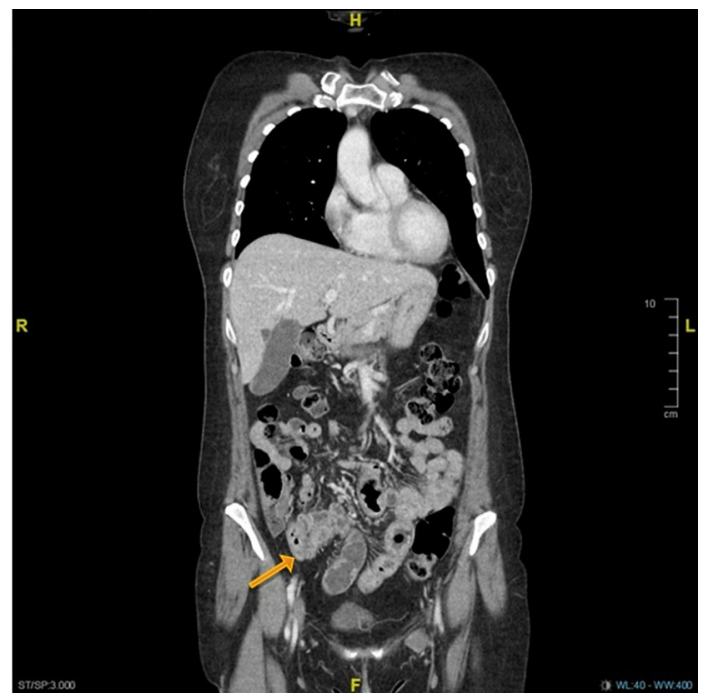

Figure 1 Contrast-enhanced coronal-view CT scan of the lower chest, abdomen and pelvis showing bowel wall thickening of the distal ileum (arrow) with numerous small volume ileocolic lymph nodes suggestive of enteritis. of colonic perforation in the study by Marthey et $a .^{2}$ Here, we report the case of a patient who had ileal perforation as a complication of terminal ileitis, without colitis, induced by combination immune checkpoint blockade.

A 52-year-old woman with a diagnosis of metastatic vulval malignant melanoma presented prior to cycle three of combination ipilimumab-nivolumab treatment, with severe abdominal pain, mouth ulcers, nausea and appetite loss. Examination
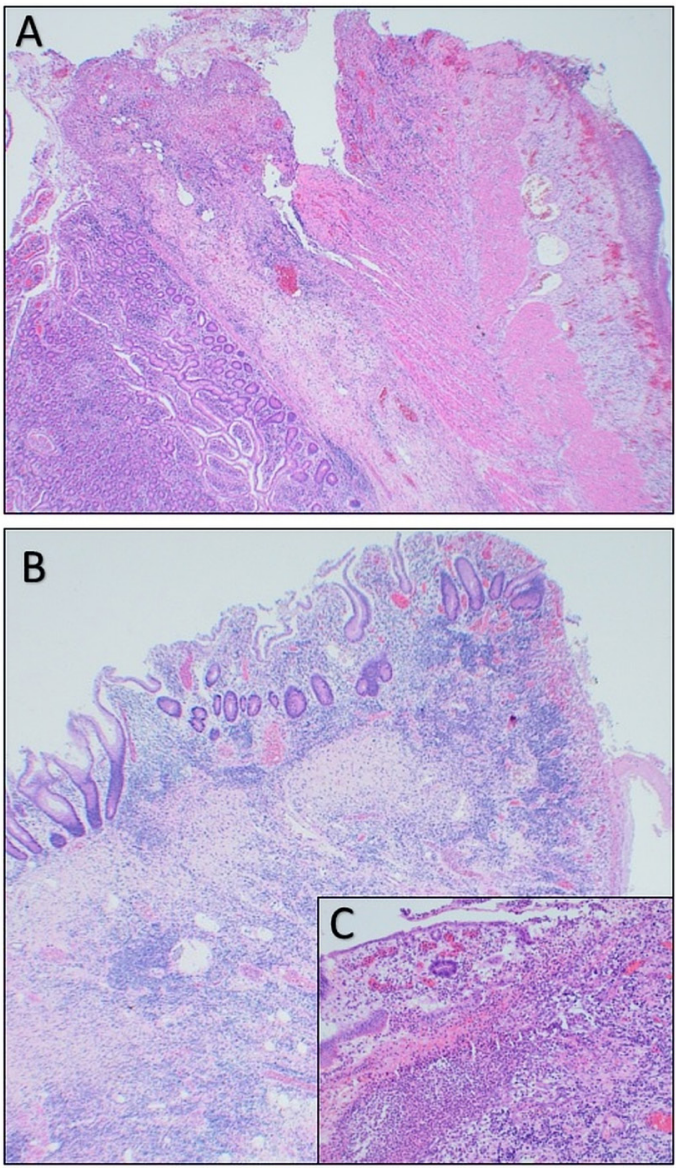

Figure 2 A shows acute transmural ischaemic necrosis of the small bowel with perforation and peritonitis ( $\mathrm{H} \& \mathrm{E}$ magnification $\times 40$ ). $B$ shows acute ischaemic changes to the small bowel with ulceration (H\&E magnification $\times 40)$. $C$ is a higher power image of acute ischaemic changes to the small bowel mucosa with ulceration ( $\mathrm{H} \& \mathrm{E}$ magnification $\times 250$ ). 
revealed generalised abdominal tenderness with guarding but no rigidity and bowel sounds present. Vital signs were within normal range. Laboratory tests were satisfactory except an

\section{Patient's perspective}

- I was offered immunotherapy after my melanoma returned, despite surgery in 2016. It was explained that the combined ipilimumab-nivolumab treatment would have side effects that could be very severe but that it was more effective than single treatment.

- After the first treatment there were no major side effects other than the lymph node in my left groin swelled up and was very painful. I had a few itchy spots develop on my legs similar to mosquito bites. There were some occasional stomach cramps and my appetite started to decline just before my second treatment.

- After the second treatment I developed mouth ulcers and the stomach cramps increased in severity, I was also sick on occasions - this reduced my appetite to zero. I was admitted to LRI and the symptoms seemed to indicate influenza - I started on steroids and once my temperature came down I was discharged.

- On the week I was due for the third treatment I was in so much abdominal pain and had not eaten properly for weeks I was admitted again. The pain seemed to increase at night and the few nights before my surgery it was unbearable and the pain relief was ineffective-I kept the other patients awake with my screaming which is not like me as I have quite a high pain threshold.

- I woke after the emergency surgery not sure of what had happened but grateful that the pain had decreased. The rest of the stay in hospital was spent getting moving and learning how to look after my stoma.

- Having a stoma is proving troublesome as I've developed a fistula and this is causing pain where the stomach contents are burning the skin. After discussion with surgery team it may be as early as May for surgery reversing the stoma.

- I am aware that I am very lucky to receive the treatment and to be clear of tumours, and that although the stoma is troublesome it could have been so much worse. I am back at work now after a phased return in January. I have also been on holiday abroad and plan another holiday before getting the stoma reversed.

- It has been very distressing but I am truly grateful and I can't thank all the people involved in my treatment enough, especially my oncology team, who were all excellent.

\section{Learning points}

- Immune checkpoint inhibitors are effective new generation of anticancer therapies but can be associated with significant immune-related adverse events (irAEs).

- Autoimmune ileitis, without colitis, is a relatively rare gastrointestinal irAE in association with immune checkpoint inhibitor.

- Careful reporting of irAEs helps to inform judgement of benefits and risks of cancer immunotherapies and aids early recognition and intervention. elevated $\mathrm{C}$ reactive protein $(89 \mathrm{mg} / \mathrm{L})$. A prompt CT scan of the chest to pelvis revealed evidence of terminal ileitis but no colitis, perforation or bowel obstruction (figure 1). An excellent tumour response was also reported. She commenced intravenous methylprednisolone $(1.5 \mathrm{mg} / \mathrm{kg} /$ day $)$ and fluids. She initially responded to steroid treatment both clinically and biochemically. However, on night 6 after admission, while an inpatient she had a sudden and significant increase in her abdominal pain. A repeat CT scan of the abdomen confirmed our clinical suspicion of bowel perforation. She underwent an urgent laparotomy where her terminal ileum was resected and an end ileostomy fashioned. At surgery, throughout the ileum, there were multiple circular areas measuring $10-20 \mathrm{~mm}$ in diameter with significant inflammation. Only the most distal lesions were resected, as removal of all lesions would have risked short bowel syndrome. Histologically, each lesion was associated with complete loss of the mucosa-only attenuated muscularis propria and serosa remained-with florid neovascularisation at the periphery of each lesion (figure 2). A single small ileal perforation was present in the centre of one lesion. There was no vasculitis. Two days postoperatively, a single dose of intravenous infliximab $(5 \mathrm{mg} /$ $\mathrm{kg}$ ) was administered, aiming to prevent further perforation of known residual inflamed sites. She made a rapid, unremarkable recovery, being discharged home 10 days postoperatively.

To our knowledge, only one case of ipilimumab-induced ileitis without colitis that resulted in ileal perforation has been reported in the literature. ${ }^{4}$ The authors hypothesise that there could be two different pathways activated against colic and ileal epitopes resulting in two distinguished pattern of gastrointestinal involvement.

In conclusion, our case study highlights the importance of early recognition of gastrointestinal irAEs of checkpoint inhibitors particularly in patients receiving combination immunotherapy. Spain et al have outlined the general approach to the management of irAEs, and this needs to be expanded. ${ }^{5}$ We call for expert consensus on clear guidelines for the management of the gastrointestinal irAEs to try preventing complications and the need for surgical intervention.

Contributors AAM conceived the case report, reviewed the literature and prepared the first manuscript draft. CJR contributed with the histopathological notes and images and reviewed the manuscript. $K B$ contributed with the surgical notes and reviewed the manuscript. GF contributed to the conception of the case report and reviewed the manuscript. All authors approved the final version of the manuscript.

Funding The authors have not declared a specific grant for this research from any funding agency in the public, commercial or not-for-profit sectors.

Competing interests None declared.

Patient consent Obtained.

Provenance and peer review Not commissioned; externally peer reviewed.

(C) BMJ Publishing Group Ltd (unless otherwise stated in the text of the article) 2018. All rights reserved. No commercial use is permitted unless otherwise expressly granted.

\section{REFERENCES}

1 Larkin J, Chiarion-Sileni V, Gonzalez R, et al. Combined nivolumab and ipilimumab or monotherapy in untreated melanoma. N Engl J Med 2015;373:23-34.

2 Marthey L, Mateus C, Mussini C, et al. Cancer immunotherapy with anti-CTLA-4 monoclonal antibodies induces an inflammatory bowel disease. J Crohns Colitis 2016;10:395-401.

3 Collins M, Michot JM, Danlos FX, et al. Inflammatory gastrointestinal diseases associated with PD-1 blockade antibodies. Ann Oncol 2017;28:2860-5.

4 Venditti $\mathrm{O}$, De Lisi $\mathrm{D}$, Caricato $\mathrm{M}$, et al. Ipilimumab and immune-mediated adverse events: a case report of anti-CTLA4 induced ileitis. BMC Cancer 2015;15:87.

5 Spain L, Diem S, Larkin J. Management of toxicities of immune checkpoint inhibitors. Cancer Treat Rev 2016;44(Supplement C):51-60. 
Copyright 2018 BMJ Publishing Group. All rights reserved. For permission to reuse any of this content visit http://group.bmj.com/group/rights-licensing/permissions.

BMJ Case Report Fellows may re-use this article for personal use and teaching without any further permission.

Become a Fellow of BMJ Case Reports today and you can:

- Submit as many cases as you like

- Enjoy fast sympathetic peer review and rapid publication of accepted articles

Access all the published articles

- Re-use any of the published material for personal use and teaching without further permission

For information on Institutional Fellowships contact consortiasales@bmjgroup.com

Visit casereports.bmj.com for more articles like this and to become a Fellow 